\title{
Evaluation of Anticonvulsive Effect of Methanol Extract of Ferula Asafoetida Gum in Mice
}

Mehrdad Karimi ${ }^{1}$, Mohsen Naseri², Mohammad Sayyah ${ }^{3}$, Mohammad Kamalinejad $^{4}$, Sepideh Amiri5 $^{5,6}$ *

\author{
${ }^{1}$ Faculty of Traditional Medicine, Tehran University of Medical Sciences, Tehran, Iran. \\ ${ }^{2}$ Faculty of Medicine, Shahed University, Tehran, Iran. \\ ${ }^{3}$ Department of Pharmacology, Pasteur Institute of Iran, Tehran, Iran. \\ ${ }^{4}$ Faculty of Pharmacy, Shahid Beheshti University of Medical Sciences, Tehran, Iran. \\ ${ }^{5}$ Shefa Neuroscience Research Center, Khatam-al-Anbia Hospital, Tehran, Iran. \\ ${ }^{6}$ Department of Animal Biology, Science and Research Branch, Islamic Azad University, Tehran, Iran.
}

\section{A BSTRACT}

I

ntroduction: There are some reports on the antiepileptic effects of genus Ferula in the traditional Persian medicine. Due to the side effects of common antiepileptic drugs, effective compounds with fewer side effects are needed. The present study examined the anticonvulsive effects of the methanol extract of Ferula in seizures induced by maximum electroshock (MES) and pentylenetetrazol (PTZ) in mice. Materials and Methods: Thirty minutes before the induction of seizures, sixty mice were divided into six groups; group I: solvent (10 mg/kg control group), group II: ethosuximide (150 mg/kg as positive control group for PTZ), group III: phenytoin $(25 \mathrm{mg} / \mathrm{kg}$ as positive control group for MES) and the fourth, fifth, and sixth groups: the methanol extract of Ferula $(100,250,500 \mathrm{mg} / \mathrm{kg})$. Results: The methanol extract of Ferula did not inhibit the occurrence of seizures induced by PTZ and MES, but significantly increased the latency time in the PTZ model. Conclusion: It seems that the methanol extract of Ferula has different effects in various models of seizures and further investigation is needed.

\section{Key words:}

1. Ferula

2. Epilepsy

3. Mice

* Corresponding Author: Sepideh Amiri

E-mail: amiri.sp65@yahoo.com 


\section{بررسى اثر ضد تشنجى عصاره ى متانولى صمغ فرولا اسافوتيدا در موش سورى}

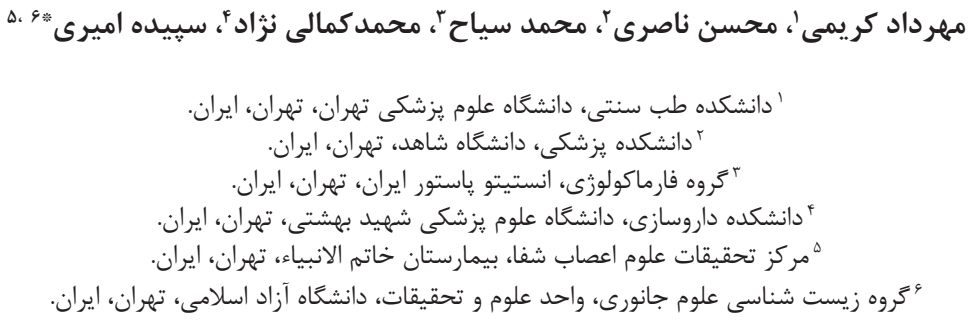

مقدمه: ززارش هايى درباره اثرات ضد تشنجى گياهان جنس فرولا در طب سنتى ايران وجود دارد.

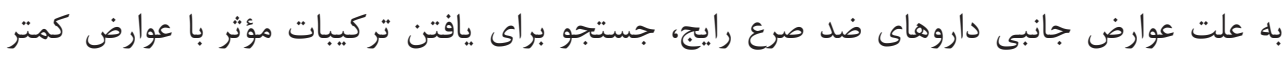

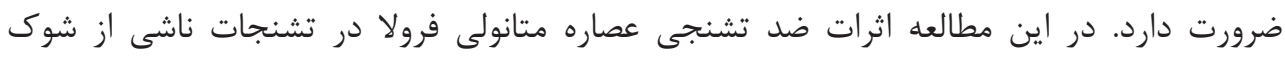

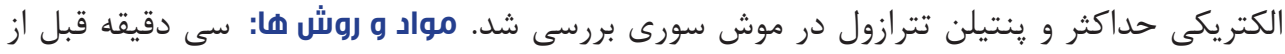

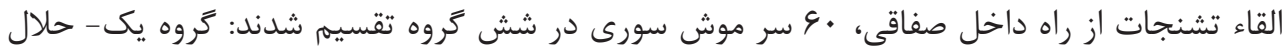

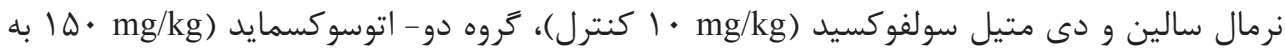

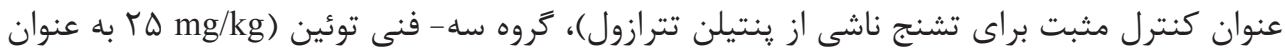

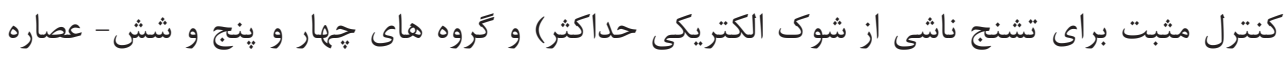

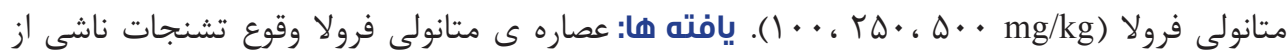

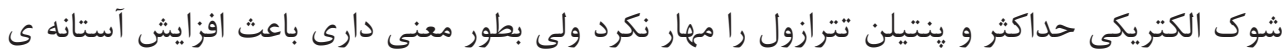

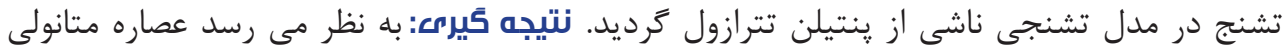

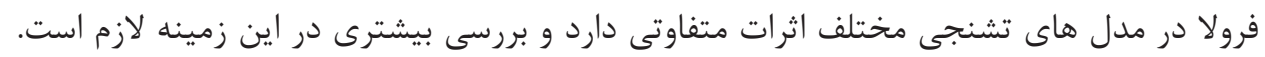


توزين و علامت كذارى شده و به آزمايشكاه منتقل شدند و

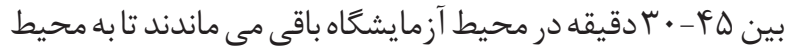

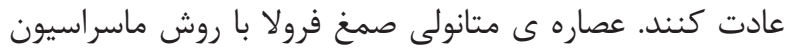

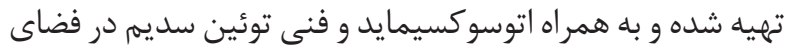

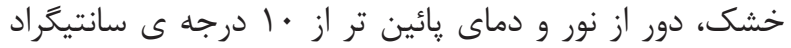

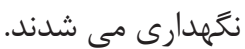

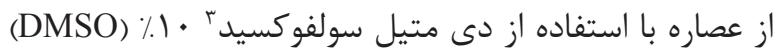

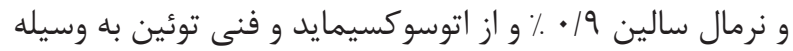

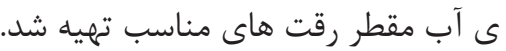

در مدل PTZ، بعد از عادت كردن موش ها به محيط، تزريق

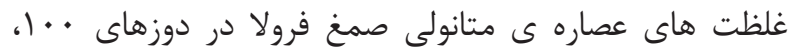

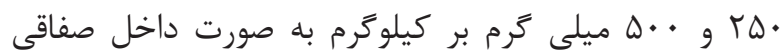

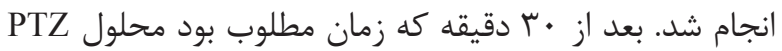

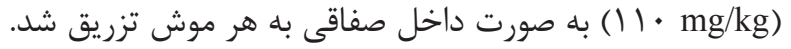

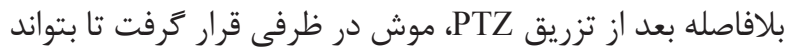

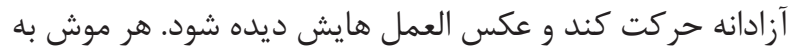

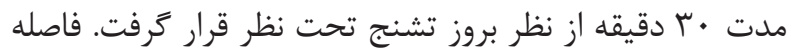

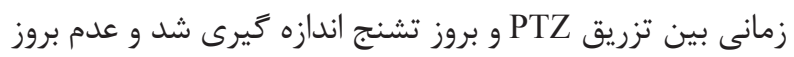

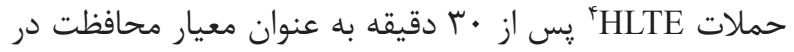
برابر PTZ در نظر كرفته شد. مركى و مير حيوانات نيز در در اين

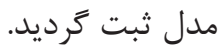

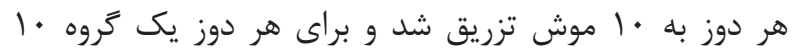

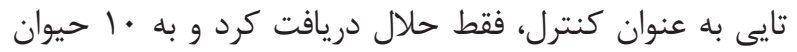

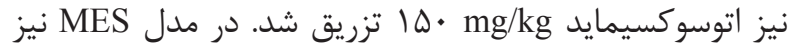

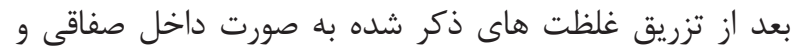

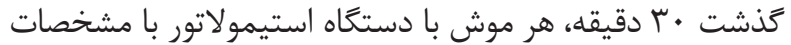

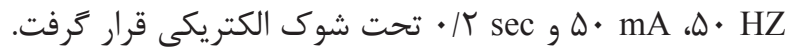

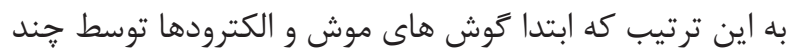

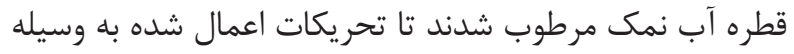

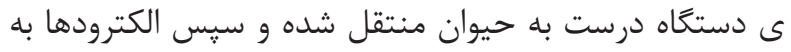

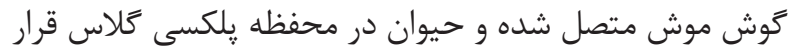
كرفت و شوك وارد شد.

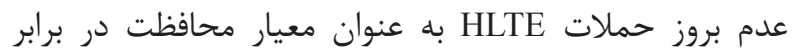

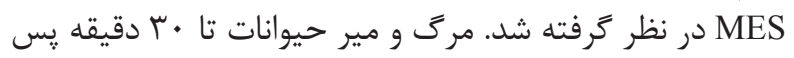

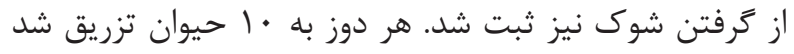

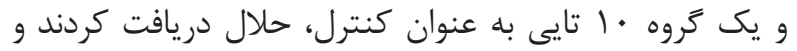

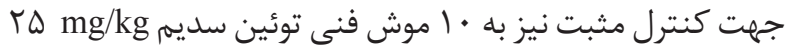

تزريق شد.

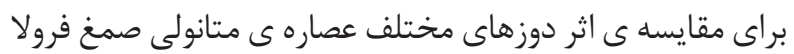

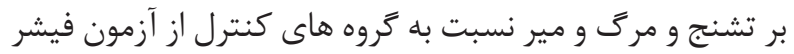

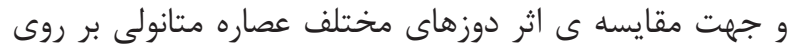
فاصله ى زمانى بين تزريق PTZ و زمان دمان بروز

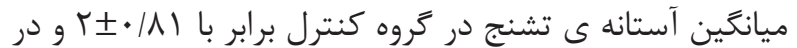

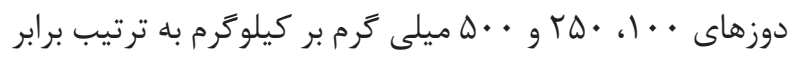

\footnotetext{
${ }_{2}^{1}$ Maximum Electroshock

${ }^{2}$ Pentylenetetrazol

${ }^{3}$ Dimethyl Sulfoxide

${ }^{4}$ Hind Limb Tonic Extensions
}

صرع دومين اختلال شايع بيمارى هاى عصبى بعد از سكته إئه

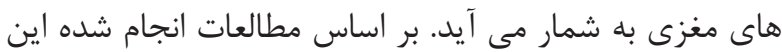

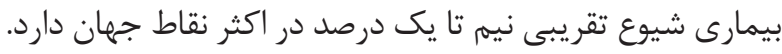

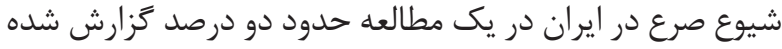

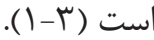

درمان بيمار مبتلا به صرع نيازمند بررسى مناسب و تشخيص

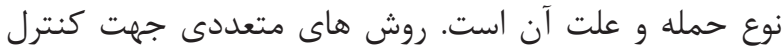

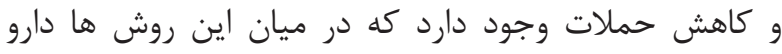

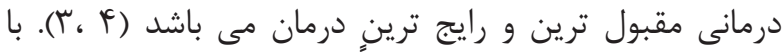

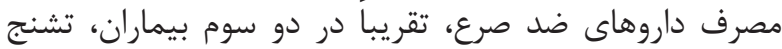

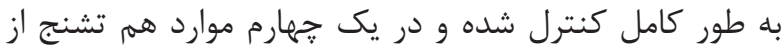

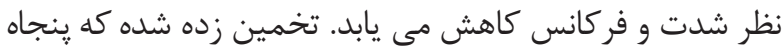

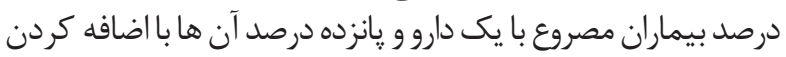

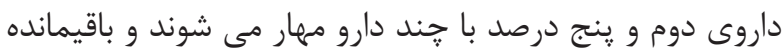

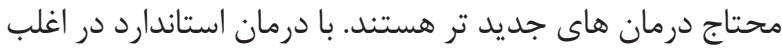

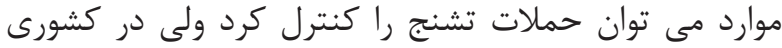

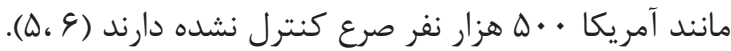

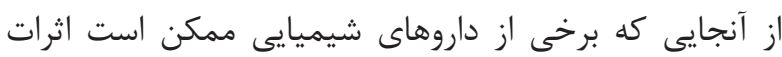

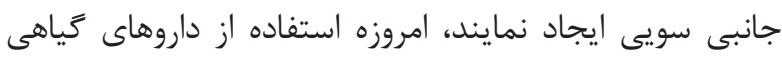

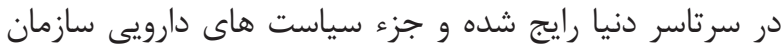

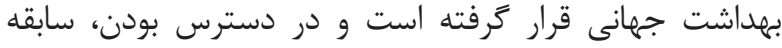

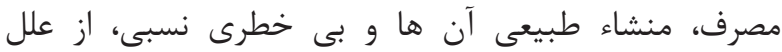

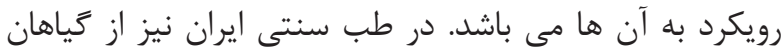

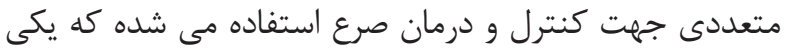

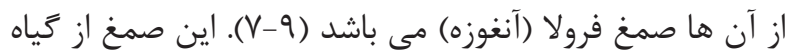
Ferula Asafoetida

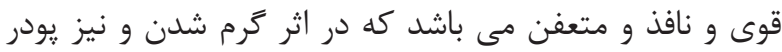

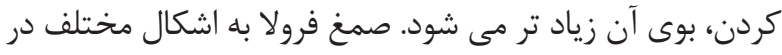

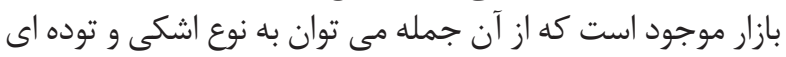

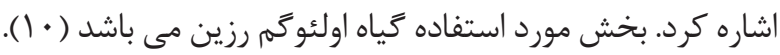

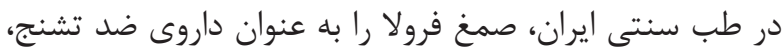

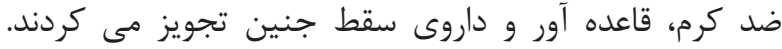

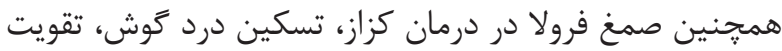

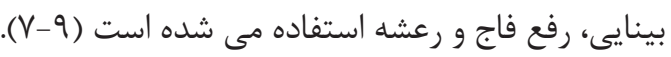

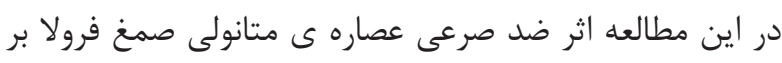
روى موش سورى بررسى شده است.

مواد و روش ها موسا جهت ايجاد تشنج از دو مدل شناخته شده مى آزمايشكاهى

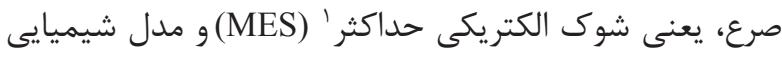

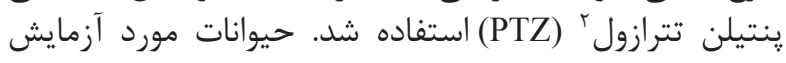

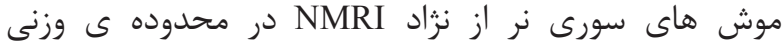

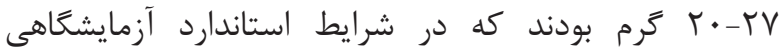
نكَهدارى مى شدند. حيوانات قبل ازئ ان انجام هر آزمايش آنش 


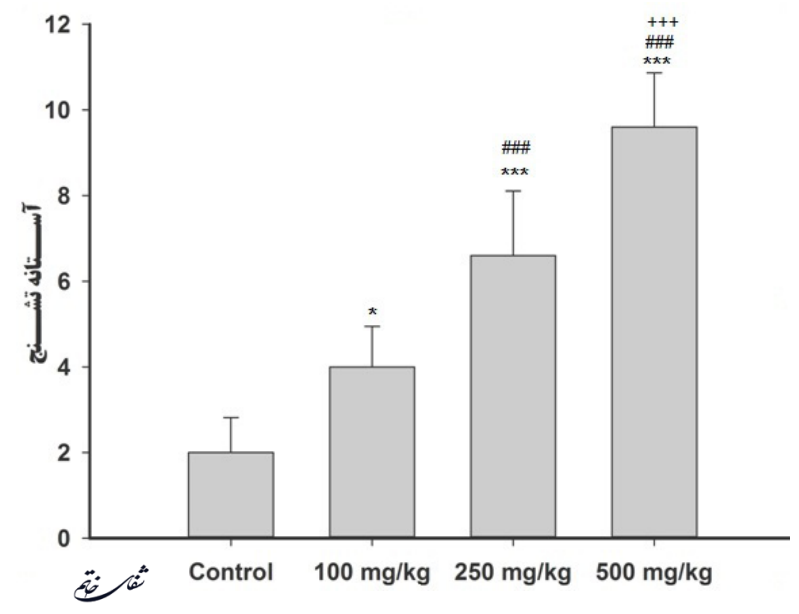

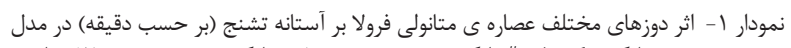

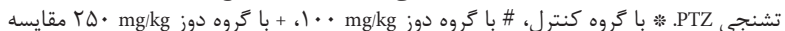

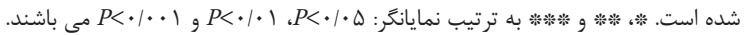

جدول r- اثرعصاره ى متانولى صمغ فرولا بر تشنج ناشى از شوك الكتريكى حداكثر.

\begin{tabular}{|c|c|c|c|c|}
\hline مرى مراوانى مر مير ها مار & موش هاى تر تشنج & تعداد & $\begin{array}{c}\text { jو } \\
\mathrm{mg} / \mathrm{kg}\end{array}$ & كروه \\
\hline $1 \cdots$ & $1 \cdots$ & 1. & 1. & 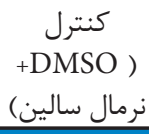 \\
\hline$\cdot$ & • & 1 & $r \Delta$ & كنترل مثبت توئين \\
\hline 9. & $1 \cdots$ & 1. & $1 \cdots$ & متانولى صماره صغ \\
\hline $\mathrm{V} \cdot$ & 9 . & 1. & $r \Delta$. & متانولى صماره صغ \\
\hline$\Lambda$. & 9 . & 1. & $\Delta \cdots$ & متانولى صماره صغ \\
\hline
\end{tabular}

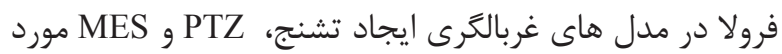

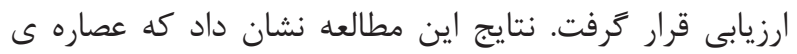

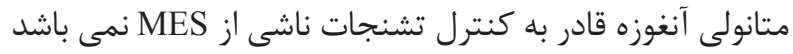

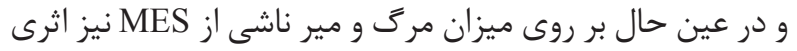

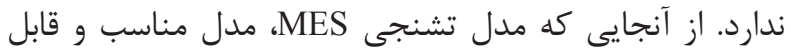

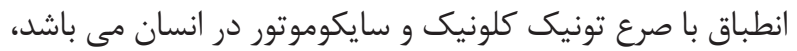

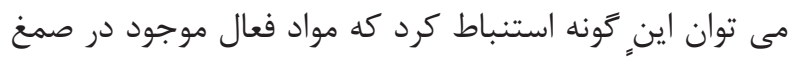

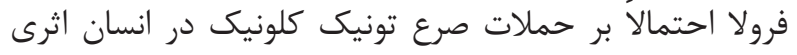

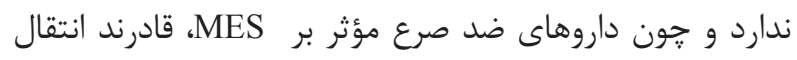

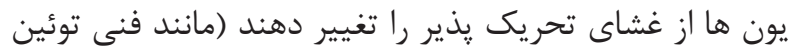

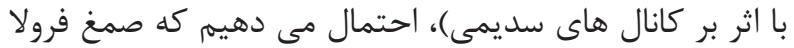

تشنج) بين كروه ها از آزمون آناليز واريانس يك طرفه (Anova)

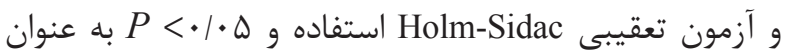
سطح آمارى معنادار در نظر كرفته شد.

يافته ها

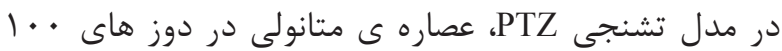

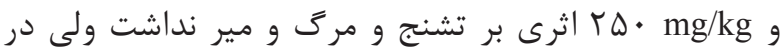
دوز

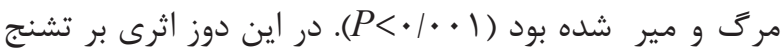

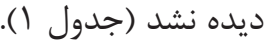

جدول ا - اثرعصاره مى متانولى صمغ فرولا بر تشنج ناشى از تزريق داخل صفاقى ينتيلن تترازول

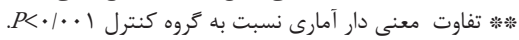

\begin{tabular}{|c|c|c|c|c|}
\hline مركى و مرير & تشروشه فراوانى & موش & $\begin{array}{c}\text { jo } \\
\text { mg/kg }\end{array}$ & كروه \\
\hline \multirow[t]{2}{*}{$1 \ldots$} & $1 \ldots$ & 1. & 1. & 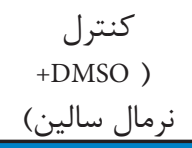 \\
\hline & $\cdot$ & 1. & 10 & كنترل مثبت \\
\hline 9. & 9. & 1. & $1 \ldots$ & 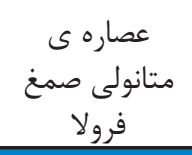 \\
\hline 4. & $\Lambda \cdot$ & 1. & ro. & متانولى صمغ \\
\hline 糈 & $V$. & 1. & $\Delta \cdots$ & متانولى صمغ ع فر \\
\hline
\end{tabular}

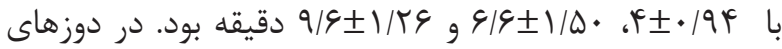

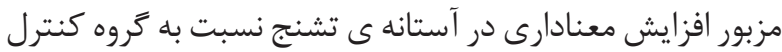

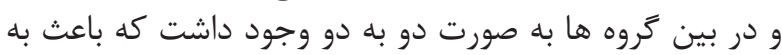

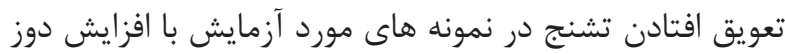

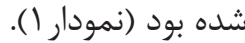
در مدل تشنجى MES، عصاره ى متانولى تأثير معنادارى بر برد (Y)، تشنج و مرك و مير نداشت (جدول كارى).

$$
\text { بحث و نتيجه كيرى }
$$

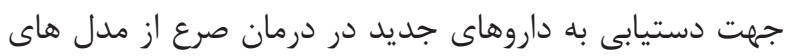

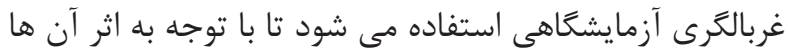

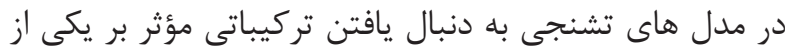

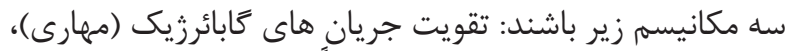

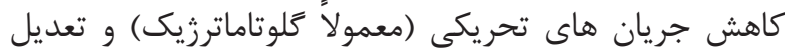

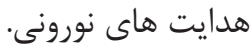
در اين مطالعه نيز اثرات ضد تشنجى عصاره ى متانولى صمغ 
جداعانه و دقيق ترى دارد و مى تواند نشانگر جدا بودن مسير

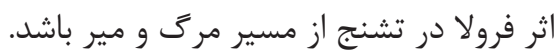

يكى از فاكتورهاى موثر در آسيب سلولى نحوه فعاليت

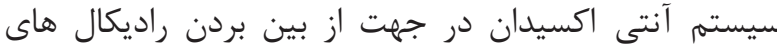

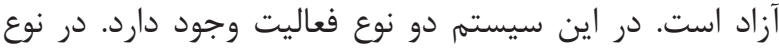

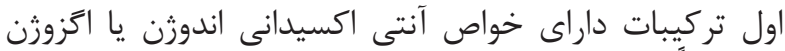

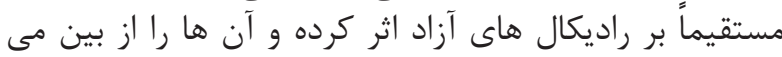

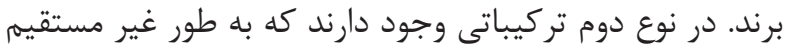

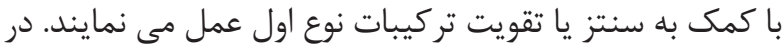

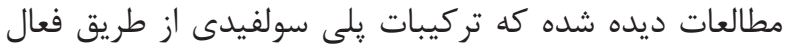

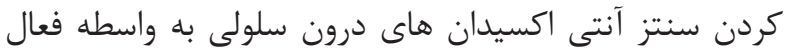

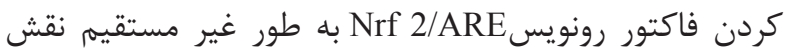

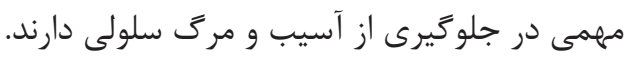

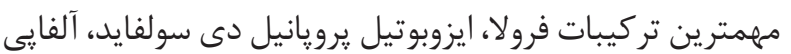

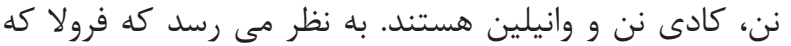

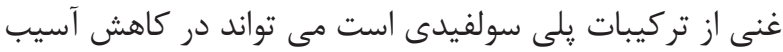

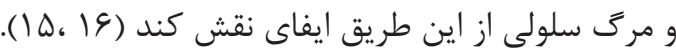

ييشنهاد مى شود كه اثرات صمغ فرولا بر روى ساير مدل هاى

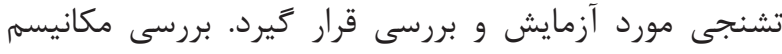

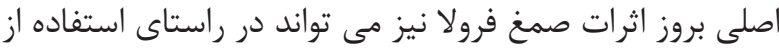

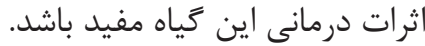

1. Sander JW. The epidemiology of epilepsy revisited. Curr Opin Neurol. 2003; 16(2): 165-70.

2. Banerjee PN, Filippi D, Allen Hauser W. The descriptive epidemiology of epilepsy-a review. Epilepsy Res. 2009; 85(1): 31-45.

3. Ebrahimi H, Shafa M, Hakimzadeh Asl S. Prevalence of active epilepsy in Kerman, Iran: a house based survey. Acta Neurol Taiwan. 2012; 21(3): 115-24.

4. Panayiotopoulos CP. The new ILAE report on terminology and concepts for organization of epileptic seizures: a clinician's critical view and contribution. Epilepsia. 2011; 52(12): 2155-60.

5. Schmidt D, Schachter SC. Drug treatment of epilepsy in adults. BMJ. 2014; 348: 254.

6. Asconapé JJ. Some common issues in the use of antiepileptic drugs. Semin Neurol. 2002; 22(1): 27-39.

7. Momen H. "Tohfeh Hakim MOMEN". Tehran: Mahmoodi; 1987 [In Persian].

8. Aghili Khorasani MH. "Makhzan Aladviyeh". Tehran: Elmi va Farhangi; 1988 [In Persian].

9. Okhvini Najari A. "Hedayat Almotealamin fi Alteb". Mashhad: Ferdowsi University; 1992 [In Persian].

10. Zargari A. "Giyahan Darooei”. 6th ed(2). Tehran:
قادر به تعديل هدايت يونى نمى باشد (1 ، ، (1).

اگرجه در اين مطالعه در مدل تشنجى PTZ كه مدلى مناسب

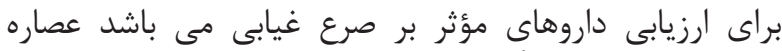

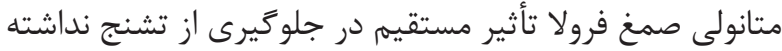

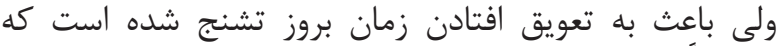

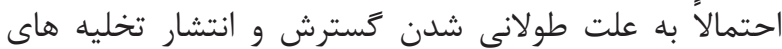

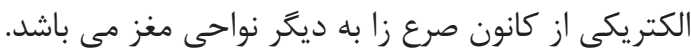

از سوى ديخر حالت گَوشه گيرى و اختلال حركتى موش ها

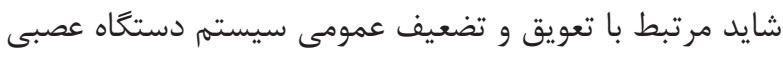

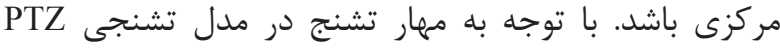

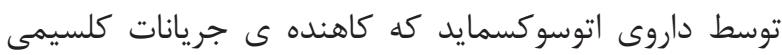

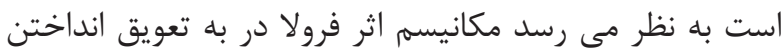

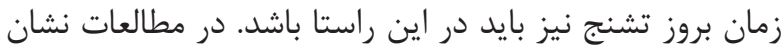

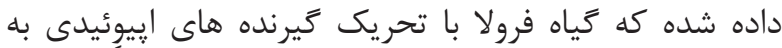

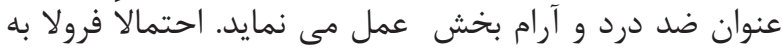

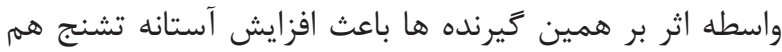

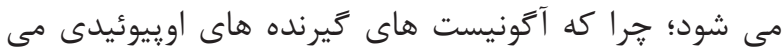

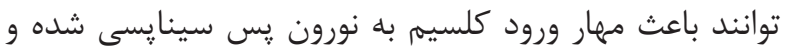

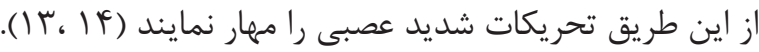
نكته قابل توجه در اين مدل كاهش ميزان مرگ و مير بعد

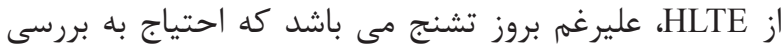

منابع

Tehran University; 1996 [In Persian].

11. Löscher W, Klitgaard H, Twyman RE, Schmidt D. New avenues for anti-epileptic drug discovery and development. Nat Rev Drug Discov. 2013; 12(10): 757-76.

12. Simonato M, Löscher W, Cole AJ, Dudek FE, Engel J Jr, Kaminski RM, et al. Finding a better drug for epilepsy: preclinical screening strategies and experimental trial design. Epilepsia. 2012; 53(11): 1860-7.

13. Mandegary A, Sayyah M, Heidari MR. Antinociceptive and Anti-inflamatory activity of the seed and root extracts of Ferula Gummosa Boiss in mice and rats. Daru. 2004; 12(2): 58-62.

14. Kiasalari Z, Khalili M, Roghani M, Heidari H, Azizi Y. Antiepileptic and Antioxidant Effect of Hydroalcoholic Extract of Ferula Assa Foetida Gum on Pentylentetrazole induced Kindling in Male Mice. BCN. $2013 ; 4(4): 21-28$

15. Kelsey NA, Wilkins HM, Linseman DA. Nutraceutical antioxidants as novel neuroprotective agents. Molecules. 2010; 15: 7792-814.

16. Iranshahy M, Iranshahi M. Traditional uses, phytochemistry and pharmacology of asafoetida (Ferula assa-foetida oleo-gumresin)-a review. J Ethnopharmacol. 2011; 134: 1-10. 